\title{
Cytotype differences modulate eco-geographical differentiation in the widespread plant Centaurea stoebe
}

\author{
Min A. Hahn ${ }^{1}$ and Heinz Müller-Schärer \\ Department of Biology, Ecology and Evolution, University of Fribourg, Chemin du Musée 10, 1700 Fribourg, Switzerland
}

\begin{abstract}
The evolution of optimal life history strategies is central for the fitness of organisms in a given environment. Besides divergent selection, other factors may determine regional patterns of differentiation and contribute to life history evolution. In a commongarden environment over three years, we examined life history differentiation across different eco-geographical regions and effects of a specialist root-insect herbivore in the widespread European plant Centaurea stoebe, spotted knapweed. This plant occurs as two cytotypes with contrasting life cycles: monocarpic diploids and polycarpic tetraploids. In addition, the tetraploid cytotype has more recently become invasive in North America. We found significant regional differentiation in traits related to the timing of reproduction and reproductive allocation, but contrasting patterns in diploids and tetraploids. In diploids the degree of regional differentiation was higher compared to native tetraploids, and in the latter compared to invasive tetraploids. Furthermore, a pronounced shift in environmental conditions between the native and introduced range could have contributed to the differentiation between native and invasive tetraploids. The study also revealed the potential of the root-mining insect herbivore Agapeta zoegana, used as a biological control organism, to increase plant performance (presumably through overcompensatory growth), especially in the polycarpic tetraploids, and more so in the introduced populations. These findings suggest that patterns of regional differentiation in $C$. stoebe may be partly determined by divergent selection, but also strongly modulated by life cycle differences among geo-cytotypes. Furthermore, our study highlights the importance in applying a comprehensive and long-term approach when studying regional differentiation in plants.
\end{abstract}

Key words: Centaurea stoebe; climate; evolutionary time; herbivory; invasive species; life history evolution; local adaptation; polyploidy; regional differentiation; spotted knapweed.

\section{INTRODUCTION}

Widespread species experiencing a large range of environmental conditions may exhibit substantial intraspecific differentiation among regions, which may reflect adaptations to the locally prevailing abiotic and biotic conditions (Linhart and Grant 1996, Galloway and Fenster 2000, Joshi et al. 2001, Kawecki and Ebert 2004). In particular, life history traits, which are directly linked to the fitness of an individual, may be strongly subjected to selection (Stearns 1992, Silvertown and Charlesworth 2001). However, although life history theory predicts the optimal adaptation of organisms to their environment as a result of natural selection (Roff 1992, Stearns 1992), recent quantitative analyses suggest that local adaptation is less common in plant populations than generally assumed (Leimu and Fischer 2008). This may be the case, because besides contrasting environmental conditions imposing divergent selection regimes, intrinsic properties of a population such as

Manuscript received 20 August 2012; revised and accepted 18 December 2012. Corresponding Editor: M. D. Eubanks.

${ }^{1}$ Present address: Forschungsanstalt Agroscope Reckenholz-Tänikon, Reckenholzstr. 191, 8046 Zürich, Switzerland. E-mail:min.hahn@unifr.ch genetic variation and gene flow (e.g., through spatial and temporal spread) may influence the actual patterns of differentiation (Slatkin 1987, Linhart and Grant 1996, Kawecki and Ebert 2004).

Differentiation may also play an important role after introduction of a species into a new range and the concomitant change in the abiotic and biotic environment, with time elapsed after introduction increasing the level of differentiation (Bossdorf et al. 2005). Invasions may result from preadaptation to the new conditions as well as from changes in species characteristics through rapid post-introduction evolution, or alternatively, genetic drift due to founder effects (Maron et al. 2004, Müller-Schärer et al. 2004, Henery et al. 2010). Knowledge on patterns of differentiation between and within the native and the introduced range will therefore also lead to a better understanding of these fundamental processes underlying successful invasions.

In this study, we use the widespread European plant Centaurea stoebe L. (spotted knapweed, Asteraceae) as a model system to investigate patterns of life history differentiation in two cytotypes with contrasting life cycles (short-lived, monocarpic diploids and perennial, polycarpic tetraploids). Tetraploid C. stoebe are of allopolyploid origin, resulting from hybridization of dip- 
loids with a second, currently unknown parental taxon (Mráz et al. 2012). Both cytotypes are native to Europe, where they occur mostly in single-cytotype populations with a large overlap of their geographical and ecological ranges (Treier et al. 2009). More recently, $C$. stoebe has become a highly invasive rangeland weed in North America (Roche and Roche 1991, Sheley et al. 1998), where so far only tetraploids have been found (Treier et al. 2009, Mráz et al. 2011). Most likely both cytotypes initially were introduced due to their largely sympatric distributional range in Europe (Treier et al. 2009) and the evidence for multiple introductions (Marrs et al. 2008). We refer to the three cytotype $\times$ continent combinations (EU2 $x$, EU4 $x$, NA4 $x$ ) as "geo-cytotypes." Although previous studies reported ample variation of life history traits between and within each geo-cytotype (Broz et al. 2009, Henery et al. 2010), it remains unknown if these traits show patterns of eco-geographical differentiation and whether similar trends are found among the geo-cytotypes.

In the framework of a three-year open-field common garden experiment (see also Hahn et al. 2012a), we examined life history differentiation of the three geocytotypes from different eco-geographical regions within each range and their responses to the specialist root herbivore Agapeta zoegana L. (Lepidoptera: Cochylidae). Interactions with this herbivore are particularly important, because it is among the most dominant species in the herbivore guild associated with roots of $C$. stoebe in Europe (Müller 1989b) and was introduced to North America as a biological control agent about 30 years ago (Müller-Schärer 1991, Steinger and MüllerSchärer 1992). Differences among geo-cytotypes, in particular in their life cycle, may result in differential effects of root-herbivory, with important consequences for life history evolution and biological control efficacy.

The specific experimental design based on a representative sample of a large number of populations allowed us to explore genetically based differentiation with regard to the presumably most important abiotic and biotic environmental gradients across regions within and between the two continents (Hahn et al. 2012a). Due to the ancestral state of diploids and their concomitant longer evolutionary history compared to tetraploids, we expect that they may exhibit a high degree of differentiation among regions. A similar pattern could also be expected in tetraploids as a consequence of high genetic variation due to their allo-polyploid origin. However, the more recent spread of tetraploids in Europe and North America may have resulted in lower levels of regional differentiation (through more recent gene flow and potential reduction of genetic variation during the invasion), while favoring more general purpose genotypes, e.g., with high phenotypic plasticity (Hahn et al. $2012 b)$.

Specifically, we asked: (1) Is there eco-geographical differentiation in life history traits in C. stoebe? (2) Do these patterns follow similar trends in monocarpic diploids and polycarpic tetraploids in Europe? (3) Is there eco-geographical differentiation also in introduced tetraploids in North America? (4) Do the three geocytotypes from different regions respond differently to a specialist root herbivore?

\section{Methods \\ Study species}

Centaurea stoebe L. (syn. C. maculosa Lam., Asteraceae; see Plate 1), spotted knapweed, is a widespread, short-lived herb native to Europe. It exists as two cytotypes, which differ in their life cycle. Diploids $(2 n=$ 18) are short-lived monocarps, while tetraploids $(2 n=$ 36) are polycarpic (Broz et al. 2009, Treier et al. 2009, Mráz et al. 2011). Centaurea stoebe was introduced multiple times into North America in the late 19th century as a seed contaminant (Roche and Roche 1991, Marrs et al. 2008), where exclusively tetraploids have become highly invasive rangeland weeds.

Agapeta zoegana (Lep.: Cochylidae) is a root-mining moth, which is among the most dominant species in the herbivore guild associated with the roots of $C$. stoebe (Müller 1989b). In late spring, adult insects emerge. Females oviposit on leaves and stems of $C$. stoebe and the larvae mine in the cortical tissue of the taproots (Müller et al. 1988). The main period of feeding is in autumn and spring. Due to its high host specificity and great potential to negatively affect the performance of $C$. stoebe, it was introduced to North America as a biological control agent about 30 years ago (MüllerSchärer 1991, Steinger and Müller-Schärer 1992), where it has established in high densities causing partly negative effects on the $C$. stoebe density (Story et al. 2000).

\section{Common garden experiment}

We grew plants of the three geo-cytotypes of C. stoebe in experimental field plots in a common garden (see also Hahn et al. 2012a). To explore genetic differentiation with regard to the main environmental gradients in the native and introduced ranges, we carefully selected a representative sample consisting of three to four natural populations from each of three eco-geographical regions per geo-cytotypes (10-12 populations per geo-cytotype in total; Appendix A) collected in 2005 (for details see Treier et al. 2009). These regions were determined by multivariate analyses of several eco-climatic parameters of a large number of natural populations (93 native [diploid and tetraploid] and 48 invasive populations [tetraploids only]). They represent geographical regions (EU-1, Ukraine; EU-2, Germany; EU-3, Hungary; NA1, Montana; NA-2, western Montana/eastern Oregon; NA-3, Oregon) with different eco-climatic conditions along analogous gradients in both continents, although largely shifted toward drier climate in the introduced range (Appendix B). The gradients from EU-1/NA-1 toward EU-3/NA-3 can be broadly characterized by 
increasing temperatures as accompanied with decreasing levels of competition.

In April 2008, seeds were individually sown in seedling trays $(2 \times 2 \mathrm{~cm}$ cells, sterilized compost $)$ in an uncontrolled glasshouse at University of Fribourg, Switzerland. In May 2008, seedlings were planted into the experimental garden in Grangeneuve, Switzerland $\left(46^{\circ} 46.533^{\prime} \mathrm{N}, 7^{\circ} 6.867^{\prime} \mathrm{E} ; 5 \mathrm{~km}\right.$ from Fribourg) in the native range of $C$. stoebe on nutrient rich grassland (monthly mean temperatures, $-1^{\circ} \mathrm{C}$ in January, $17.6^{\circ} \mathrm{C}$ in July; mean annual precipitation, $1118 \mathrm{~mm}$ ). We established a total of 36 plots $(2 \times 2 \mathrm{~m}, 2 \mathrm{~m}$ distance $)$ in a randomized block design ( 3 geo-cytotypes $\times 3$ regions $\times$ 2 herbivore treatments $\times 2$ blocks) (for details see Hahn et al. 2012a). Seedlings of the same geo-cytotype and region were pooled (three to four populations; equal numbers of seedlings from each population) to create a total of nine artificial populations (three European diploid and tetraploid populations each and three North American tetraploid populations; Appendix A), which were also used for a comparative demographic study (Hahn et al. 2012a). Within each plot, 81 seedlings were planted in $9 \times 9$ rows $(0.2 \mathrm{~m}$ distance $)$ including two rows as a buffer to reduce edge effects and crosspollination between plots. The plots were continuously weeded and once a year in summer before applying the herbivore treatment, we reduced mice infestation by exhaust emission without any expected effects on herbivores or plants.

\section{Herbivore treatment}

We studied the responses of the geo-cytotypes from different regions to the specialist insect herbivore Agapeta zoegana, which was collected each year (20082010) in North America and reared at University of Fribourg, Switzerland (for details see Hahn et al. 2012a). In order to attain high attack rates, different approaches and herbivore loads were used in the different years. In 2008, all plots were covered with $1-\mathrm{m}^{3}$ cages $(0.5-\mathrm{mm}$ nylon mesh), and four to eight pairs of adult A. zoegana were released into each herbivore plot. After two weeks (life span of adult insects was only a few days), the cages were removed to allow pollination. In 2008 and 2009, we placed leaf pieces with eggs of $A$. zoegana onto the bases of rosettes or stems of the plants. Eighty to 120 and 960 eggs were transferred into each herbivore plot in 2008 and 2009, respectively. In 2010, 150 newly hatched larvae were transferred in each herbivore plot on the plants using a fine brush. To assess infestation levels, we infested marked control plants in the buffer zone of each plot (in 2008 and 2009), and dissected the roots in the following spring as well as roots from central plants at the end of the experiment.

\section{Measurements}

Each spring and fall from 2008 to 2010, we recorded survival, bolting, presence and number of accessory rosettes, number of shoots, and the height of the highest shoot of the plants in the central $1-\mathrm{m}^{2}$ subplot of each plot ( 25 plants per plot, 900 plants in total). To assess flowering phenology and fecundity we counted the number of buds, flower heads, and seed heads on the three largest shoots from five plants per plot within one to three days in September 2008, August 2009, and August 2010. A flowering phenology index (FPI) was calculated for each individual as FPI $=0.5[f /(b+f+s)]$ $+[s /(b+f+s)]$ with number of buds $b$, flower heads $f$, and seed heads $s$, referring to the stage of reproductive development ( 0 , only buds; 1 , only seed heads). The number of seeds was counted in nine mature seed heads from each of five plants per plot (three seed heads from each of the three largest shoots). Fecundity (seed production) of bolting plants was estimated by multiplying the plot-average number of seeds per seed head by the plot-average number of flower heads per shoot by the number of shoots per plant. Cumulative fecundity (including plants that did not reproduce) was estimated by multiplying the plot-average number of seeds per seed head by the plot-average number of flower heads per shoot by the number of shoots of each plant for each year summed over all years.

\section{Statistical analyses}

Differences in life history traits among plants from different regions, geo-cytotypes, and herbivore treatments were analyzed using linear mixed models (LMMs) for normally distributed data and generalized linear mixed models (GLMMs) with the logit link function for binomially distributed data. Data were transformed if necessary to satisfy test assumptions. A first analysis included only data of diploids and tetraploids from Europe to test for differences among plants from European regions, cytotypes, and herbivore treatments. Models were fitted using region, geocytotype, and herbivore treatment and their interactions as fixed and plot nested in block as random factors. In a second analysis, differences among plants from North American regions and their responses to herbivores were examined (excluding European cytotypes) with region, herbivore treatment, and their interaction as fixed and plot nested in block as random factors. The third analysis examined differences between native European and invasive North American tetraploids (excluding EU2 $x$ from the data set). GLMMs were fitted with geo-cytotype, herbivore treatment, and their interaction as fixed effects, and plot, block, and regions as random effects. LMMs were done in a two-step procedure starting with region, herbivore treatment, and their interactions in the fixed and plot nested in block in the random part of the model followed by a second nested model including geo-cytotype, herbivore treatment, and their interaction as fixed factor to assess the region effect. Selection of minimal adequate models was done by removing nonsignificant terms from the full model either using Akaike's information criteria following Bolker et al. 

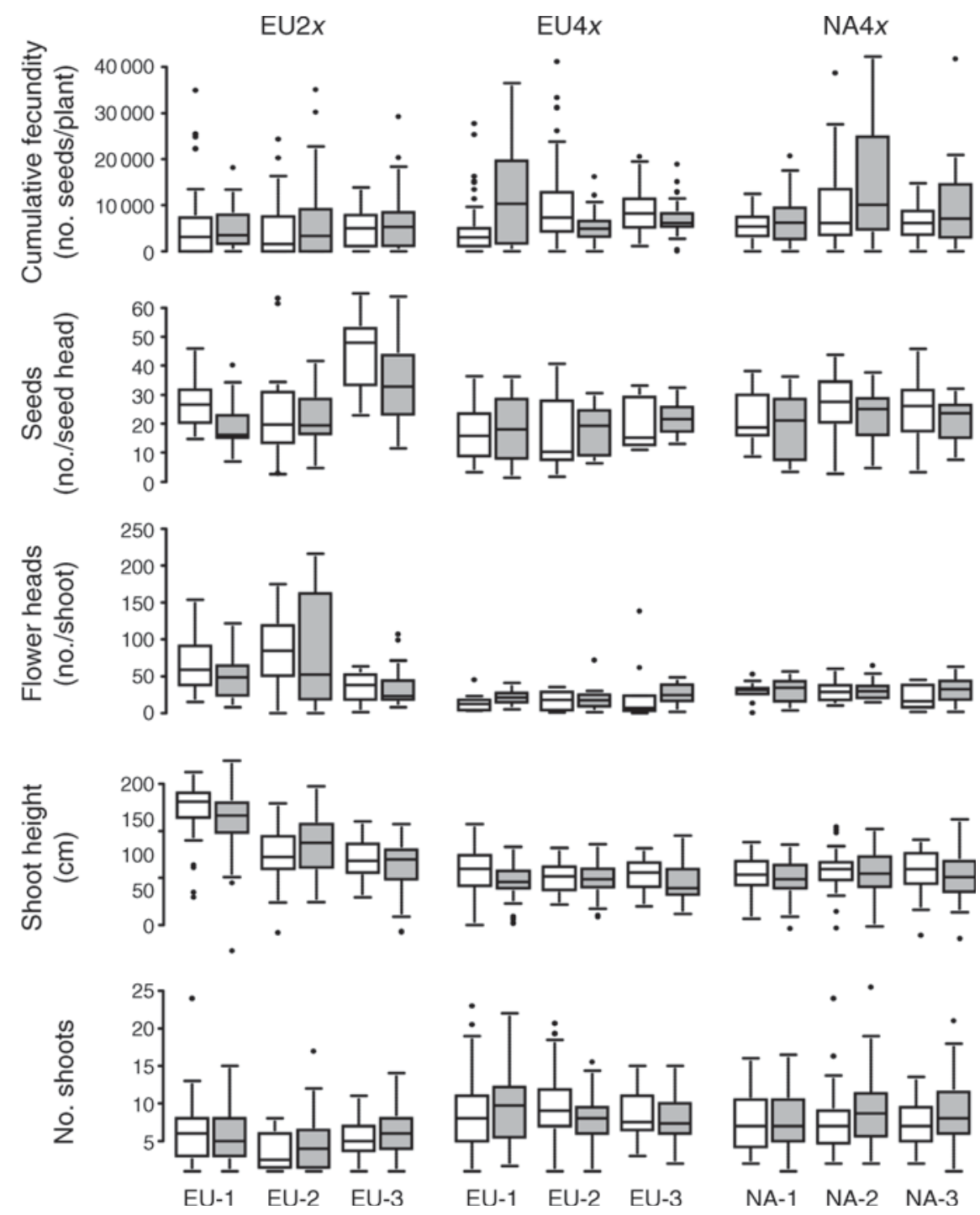

FIG. 1. Differences in life history traits related to fecundity and reproductive allocation of the three geo-cytotypes (European diploids, European tetraploids, and North American tetraploids) of Centaurea stoebe (spotted knapweed) from different ecogeographical regions (EU-1, Ukraine; EU-2, Germany; EU-3, Hungary; NA-1, Montana; NA-2, western Montana/eastern Oregon; NA-3, Oregon) in the native (Europe) and introduced (North America) range, as well as effects of the specialist root-mining moth herbivore Agapeta zoegana. Open boxes represent plants of the control treatment (no herbivores); gray boxes represent plants from the herbivore-addition treatment. Boxplots show median (line in the box), upper and lower quartiles (start and end of box), whiskers that extend to the most extreme data point that is no more than 1.5 times the interquartile range from the box, and outliers. Cumulative fecundity is the estimated number of seeds per plant over the entire life span; seeds per seed head is the average number of seeds per seed head at first flowering; flower heads per shoot is the average number of flower heads per shoot at first reproduction; shoot height is the average height of shoots; shoots is the average number of shoots per plant.

(2009) (for GLMMs), or based on likelihood-ratio tests with maximum likelihood (ML) estimations (for LMMs). Parameter estimates were calculated using restricted maximum likelihood (REML). All analyses were performed with the statistical software $\mathrm{R}(\mathrm{R}$ Development Core Team 2009) using the "lmer" function in the "lme4" package for GLMMs (Bates and Maechler 2009) and "lme" in the "nlme" package for LMMs (Pinheiro et al. 2009).

\section{RESUlTS}

Differentiation in diploids and tetraploids from Europe

In line with previous studies (see e.g., Henery et al. 2010) we found differences in several life history traits between the cytotypes (Figs. 1 and 2; Appendix C: Table C1). Several life history traits of the two European cytotypes also showed patterns of regional differentiation; however this did not translate into differences in fecundity 

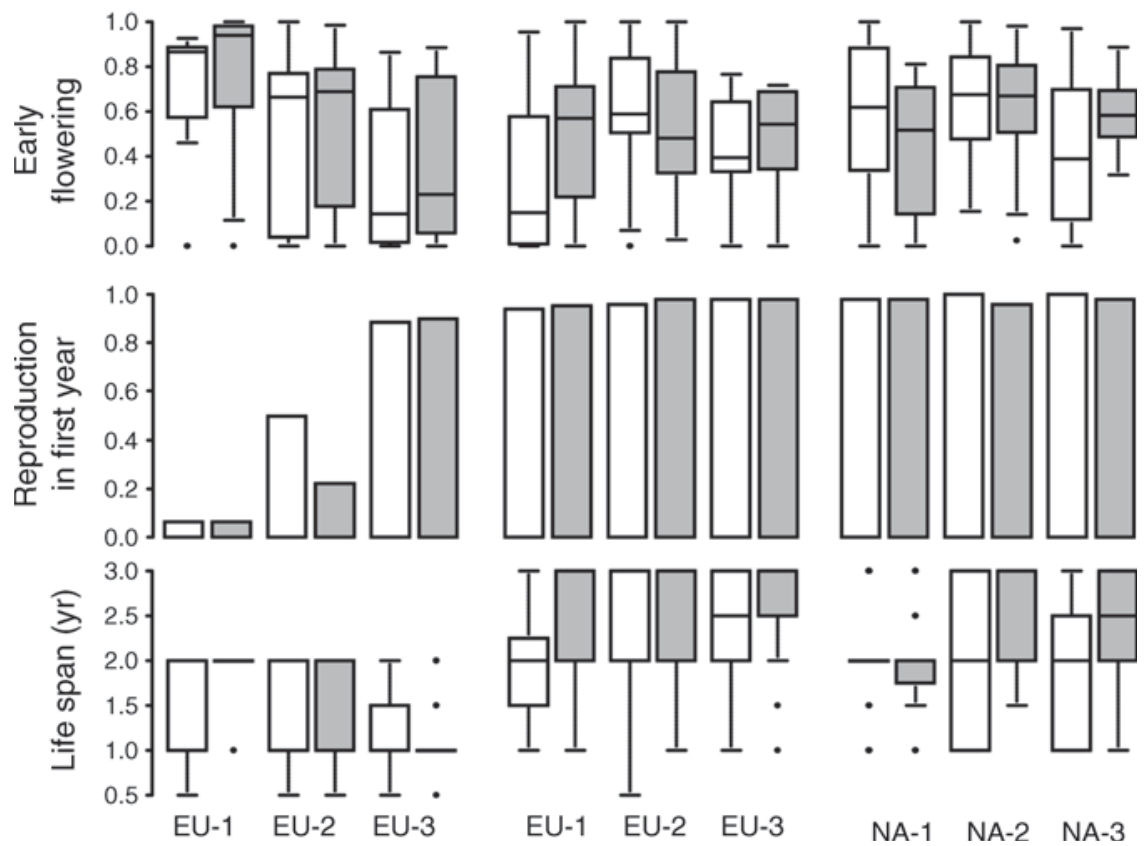

FIG. 2. Differences in life history traits related to survival and timing of reproduction of the three geo-cytotypes of C. stoebe from different eco-geographical regions in the native and introduced range and effects of the specialist root herbivore A. zoegana. Open boxes represent plants of the control treatment (no herbivores); gray boxes represent plants from the herbivore-addition treatment. Boxplots (early flowering and life span) show median (line in the box), upper and lower quartiles (start and end of box), and whiskers that extend to the most extreme data point, which is not more than 1.5 times the interquartile range from the box and outliers. Barplots (reproduction in first year) show means. Early flowering is the average flowering phenology index (FPI); reproduction in first year is the proportion of plants with first reproduction in the first vs. the second year; life span is the average life span in number of years.

among regions (Fig. 1; Appendix C: Table C1). Only a few diploids flowered in the first year from EU-1 (5\%), but $34 \%$ from EU-2 and even $91 \%$ from EU-3 (average values of the control and herbivore treatment). In contrast, most tetraploids $(>95 \%)$ started reproduction in the first year without significant regional differences (Fig. 2). Furthermore, diploids from EU-1 showed an earlier flowering phenology as compared to EU-2 $(P<0.04)$ as well as the latter compared to EU-3 $(P<0.003)$ and several regional differences in resource allocation traits (Appendix C: Table C1), whereas in tetraploids no differences among regions were found in these traits (Figs. 1 and 2).

In general, the level of differentiation was higher in European diploids compared to European tetraploids (Table 1). Five traits were regionally differentiated in diploids only (year of first reproduction, average flowering phenology, number of shoots at first reproduction, height of shoots at first reproduction, number of seeds per seed head at first reproduction) and in one trait (number of accessory rosettes at first reproduction) differentiation was more pronounced in diploids than in European tetraploids (Table 1).

\section{Differentiation in tetraploids from North America}

Compared to European tetraploids, North American tetraploids produced more seeds at first reproduction
$(E U 4 x, 2325 \pm 387$ seeds, NA4x, $3543 \pm 474$ seeds, mean $\pm \mathrm{SE}, P<0.04)$, but cumulative fecundity did not differ between these two groups (Appendix C: Table $\mathrm{C} 2$ ). Flowering phenology was more advanced in North American tetraploids in the first $(P<0.004)$ and third year $(P<0.02)$.

Furthermore, tetraploids from different North American regions significantly differed in fecundity (Fig. 1; Appendix C: Table C3). Cumulative fecundity increased in plants from NA-1 to NA-3 $(P<0.007)$ and from NA3 to NA-2 $(P<0.03$; Fig. 1$)$. In addition, flowering phenology of plants from NA-3 was delayed compared to the other regions in the second and third year $(P<$ $0.0001)$. The level of regional differentiation was slightly lower in North American tetraploids (10 traits differentiated of 34 traits total) compared to European tetraploids (12 traits differentiated of 25 traits total) (see also Table 1).

\section{Responses of the three geo-cytotypes to root-herbivory}

In 2008 and $2009, \sim 20 \%$ of the plants in the herbivore plots were successfully infested with one or two larvae of A. zoegana per plant (similar attack across geocytotypes, $N=36$ ). In $2010,39 \%$ of the plants in the herbivore plots were infested with an average of 2.16 larvae per plant $(N=64)$. Infestation differed between 
TABLE 1. Regional differentiation in life history traits of the three geo-cytotypes of spotted knapweed, Centaurea stoebe.

\begin{tabular}{lccc}
\hline \hline \multicolumn{1}{c}{ Variable } & \multicolumn{3}{c}{ Region effect } \\
\cline { 2 - 4 } & EU2x & EU4x & NA4x \\
\hline Fecundity & & & \\
Seeds R1 & $\mathrm{ns}$ & $\mathrm{ns}$ & $*$ \\
Seeds total & $\mathrm{ns}$ & $\mathrm{ns}$ & $* * *$ \\
Life cycle & & & \\
Life span & $\mathrm{n} * *$ & $* * *$ & $\mathrm{~ns}$ \\
Survival to R1 & $* \mathrm{~ns}$ & $\mathrm{~ns}$ \\
Survival after R1 & $*$ & $\mathrm{~ns}$ \\
Survival R1 to R2 & $\mathrm{ns}$ & $\mathrm{ns}$ & $\mathrm{ns}$ \\
Reproduction events & $\mathrm{ns}$ & $\mathrm{ns}$ & $\mathrm{ns}$ \\
Year of first reproduction & $* * *$ & $\mathrm{~ns}$ & $\mathrm{~ns}$ \\
Accessory rosettes formation R1 & & & $\mathrm{ns}$ \\
No. accessory rosettes R1 & $* *$ & $*$ & $\mathrm{~ns}$ \\
Flowering phenology 2008 & $\mathrm{ns}$ & $\mathrm{ns}$ & $\mathrm{ns}$ \\
Flowering phenology 2009 & $\mathrm{ns}$ & $\mathrm{ns}$ & $\mathrm{ns}$ \\
Mean flowering phenology & $* *$ & $\mathrm{~ns}$ & $*$ \\
Reproductive allocation & & & \\
Shoots R1 & $* *$ & $\mathrm{~ns}$ & $\mathrm{~ns}$ \\
Mean number of shoots & $\mathrm{ns}$ & $\mathrm{ns}$ & $\mathrm{ns}$ \\
Height of shoots R1 & $* * *$ & $\mathrm{~ns}$ & $\mathrm{~ns}$ \\
Flower heads per shoot R1 & $\mathrm{ns}$ & $\mathrm{ns}$ & $\mathrm{ns}$ \\
Seeds per seed head R1 & $* * *$ & $\mathrm{~ns}$ & $\mathrm{~ns}$ \\
Seeds per seed head R2 & $* *$ & $* *$ & $\mathrm{~ns}$ \\
Traits differentiated/traits total & $10 / 19$ & $5 / 19$ & $3 / 19$ \\
\hline
\end{tabular}

Notes: Overview of region effects in traits that were measured in all geo-cytotypes. R1 is first reproduction, and $\mathrm{R} 2$ is second reproduction. Only traits with statistically significant effects (indicated by asterisks) were inlcuded in the minimal model, based on AIC.

$* P<0.05 ; * * P<0.01 ; * * * P<0.001 ;$ ns, not statistically significant.

geo-cytotypes in 2010 (EU2 $x$, no infested plants, $N=12$, most diploids died before 2010; EU4x, 56\% infested, $N=$ 27, 1.8 larvae per plant; NA4 $x, 40 \%$ infested, $N=25,2.7$ larvae per plant)

Generally, the herbivore treatment increased the life span of plants $(P<0.001)$, and in contrast to diploids, survival after flowering in European tetraploids $(P<$ 0.04; Appendix C: Table C1). In diploids, the production of accessory rosettes at first reproduction (i.e., an approximation for survival after flowering) was reduced by the herbivore treatment $(P<0.02$; Appendix $\mathrm{C}$ : Table C1). In European tetraploids, some negative effects of the herbivores on reproductive allocation were observed at the second and third reproduction. For both European diploids and tetraploids, EU-2 plants remained unaffected, whereas in EU-3 plants and even more pronounced in plants from EU-1 the herbivore treatment resulted in earlier flowering in the second $(P<$ $0.01)$ and third year (4x only; $P<0.006$; Fig. 2 and Appendix C: Table C1).

In North American tetraploids, fecundity at third reproduction increased with herbivores compared to European tetraploids (see Appendix C: Table C2). In general, survival (life span $[P<0.01]$, survival after first $[P<0.05]$, from first to second $[P<0.02]$, and from second to third reproduction [only trend, $P<0.07$ ]) increased in North American tetraploids treated with herbivores (Appendix C: Table C2). Furthermore, the number of reproduction events increased $(P<0.02)$, and at third reproduction more plants produced accessory rosettes $(P<0.006)$ in the herbivore plots (Appendix C: Table C2). North American tetraploids produced more shoots at second reproduction $(P<$ $0.05)$ and on average $(P<0.02)$ when treated with herbivores, whereas no effects were found in European tetraploids. Flowering in the second and third year and on average, was delayed in the herbivore treatment in plants from NA-1, not affected in plants from NA-2, but advanced in plants from NA-3 (Fig. 2).

\section{Discussion}

This is the first study that compares patterns of ecogeographical life history differentiation among two cytotypes in a common garden experiment over several years. We found contrasting patterns of differentiation in the three geo-cytotypes of $C$. stoebe, which may result from a combination of divergent selection (with regard to eco-geographic regions and herbivory) and differences among the cytotypes in life cycle, genetic variation, and gene flow. This provides important insights into life history evolution of this species with potential consequences for its invasion success.

\section{Regional differentiation in the three geo-cytotypes}

The three geo-cytotypes of $C$. stoebe showed contrasting patterns of differentiation among eco-geographical regions in several life history traits. In general, diploids revealed higher levels of regional differentiation as compared to European tetraploids. In all geocytotypes, mainly traits related to the timing of reproduction showed high differentiation among regions, which is in line with several other studies suggesting strong selection on flowering traits (e.g., Reinartz 1984, Kalisz and Wardle 1994, Franks et al. 2007). Interestingly, while most polycarpic tetraploids flowered already in the first year, monocarpic diploids varied from predominant reproduction in the first year in EU-3 toward predominant reproduction in the second year in EU-1. Such changes from annual to biennial strategies may evolve under distinct environmental conditions affecting juvenile survival. Annuals may evolve if survival to reproduction is low, in contrast, biennials are more likely to evolve if survival is higher (Cole 1954, Charnov and Schaffer 1973, Hart 1977, Klinkhamer et al. 1997, Metcalf et al. 2003). The regional variation in the year of flowering in European diploids may most probably reflect adaptation to increasing temperatures and accompanying decreasing levels of competition from EU-1 toward EU-3. Warmer temperatures may increase water stress, reduce juvenile survival, and eventually favor reproduction in the first year. A more rapid phenological development of flowering has previously been reported in association with increasing temperature (e.g., in Campanulastrum americanum; Haggerty and Galloway 2011) and increasing water stress (e.g., in Brassica rapa; Franks et al. 
2007). Coincidentally, higher levels of competition (mainly with grass) toward EU-1 may favor a biennial strategy, because diploids delaying reproduction until the second year may be capable of faster and more vigorous growth in the year of flowering due to accumulated resources. Similar results have been found in a field experiment on Oenothera biennis, in which a biennial life cycle was favored in moderately productive environments, whereas an annual life cycle was advantageous in low-productivity environments (Johnson 2007). As a potential consequence, flowering phenology of diploids was more advanced in EU-1 resulting in earlier seed set. Subsequent germination in fall may provide an advantage over plants germinating in spring (Cook 1980, Masuda and Washitani 1992, Donohue 2002). Also the observed regional pattern in resource allocation of diploids is well in line with this. In EU-1, plants invested more into growth (taller plants, more shoots, early reproduction), while plants from EU-3 were smaller, but increased investment into seed production per flower head.

In contrast, despite expected increased genetic variation due to their allo-polyploid origin (Mráz et al. 2012), regional differentiation in polycarpic European tetraploids was in general lower compared to diploids, which could be explained by several mutually nonexclusive hypotheses. The prolonged life span of tetraploids may generally relax resource limitation (over time) and therefore lower selection on optimal strategies, while allowing for increased range of phenotypic responses, as found e.g., in Mimulus guttatus (van Kleunen 2007). Furthermore, due to their ancestral state, the extended evolutionary time might have allowed diploids to develop more pronounced adaptations to local conditions as compared to polyploids. In addition, the supposed origin of tetraploids in the Balkan region and a more recent spread to Western Europe (Ochsmann 2000, Korneck 2004, Welss et al. 2008) potentially may have led to maintenance of lower differentiation due to homogenizing gene flow and selection for traits that predispose tetraploids as being good colonizers, such as high phenotypic plasticity (Richards et al. 2006, Hahn et al. 2012b) and the ability to reproduce early in life, combined with high fecundity.

In contrast to the low regional differentiation of tetraploids in Europe, our study revealed trait differences between native and invasive tetraploids, generally indicating increased performance of the invasive cytotype in accordance with previous studies (Ridenour et al. 2008, Broz et al. 2009, Henery et al. 2010, Mráz et al. 2011, Hahn et al. 2012a). In addition, a few traits showed differentiation even among regions within the introduced range. This is surprising, as tetraploids were introduced to North America only about 130 years ago with an expected reduced genetic variation. Despite this rather short time period for adaptation to the new conditions, our results are consistent with previous studies suggesting potential rapid evolutionary changes promoting the invasion of tetraploids in North America (Henery et al. 2010, Hahn et al. 2012a). In particular, the pronounced and much larger shift in the environmental niche between the native and introduced range as compared to the environmental range within each range (Treier et al. 2009) may have resulted in substantial divergent selection on introduced vs. native genotypes. With regard to adaptation of introduced populations to the novel conditions, the differences between European and North American tetraploids may be underestimated in this study as the warmer and drier conditions in the introduced range are expected to be more stressful for the plants compared to the conditions in this experiment. Furthermore, although there is strong evidence for multiple introductions to North America (Marrs et al. 2008), ongoing extensive molecular marker studies are needed to explore the geographic origin of introduced populations to exclude the alternative hypothesis of genetic drift due to founder effects in explaining the observed patterns.

Surprisingly, although regional differentiation in several traits of the three geo-cytotypes are consistent with expectations of local adaptation, fecundity as an estimate for fitness did generally not differ among regions of origin. This may indeed indicate that populations from different regions may be locally adapted in different ways (i.e., different strategies). In addition, the lack of differentiation in fecundity may be due to only little selection for differential performance of the plants at the experimental site with largely favorable conditions (high nutrient levels, no water stress, and low competition). In order to conclude that observed differentiation among regions indeed reflects local adaptation, explicit testing for reciprocal performance in the different environments is required (Kawecki and Ebert 2004, Bischoff et al. 2006).

\section{Responses to herbivores}

Herbivores may play an important role in the evolution of contrasting plant life histories. For example, reduced adult plant survival has been suggested to favor monocarpy over polycarpy (Cole 1954, Charnov and Schaffer 1973, Hart 1977, Klinkhamer et al. 1997, Metcalf et al. 2003). Therefore, differences in responses to herbivores among geo-cytotypes from different regions may elucidate differences in plantherbivore coevolutionary histories.

In our study, herbivores mainly affected traits related to the timing of flowering. In EU-3 and EU-1, the herbivores led to a shift in flowering phenology toward earlier reproduction, while in plants from EU-2 no effect was detected. These differences could result from a combination of gradually increasing temperatures from EU-1 to EU-3 promoting rapid development and early flowering (Haggerty and Galloway 2011) and differences in herbivore abundance among the three regions. For the herbivore guild associated with the roots of $C$. stoebe, high species diversity and infestation levels were 


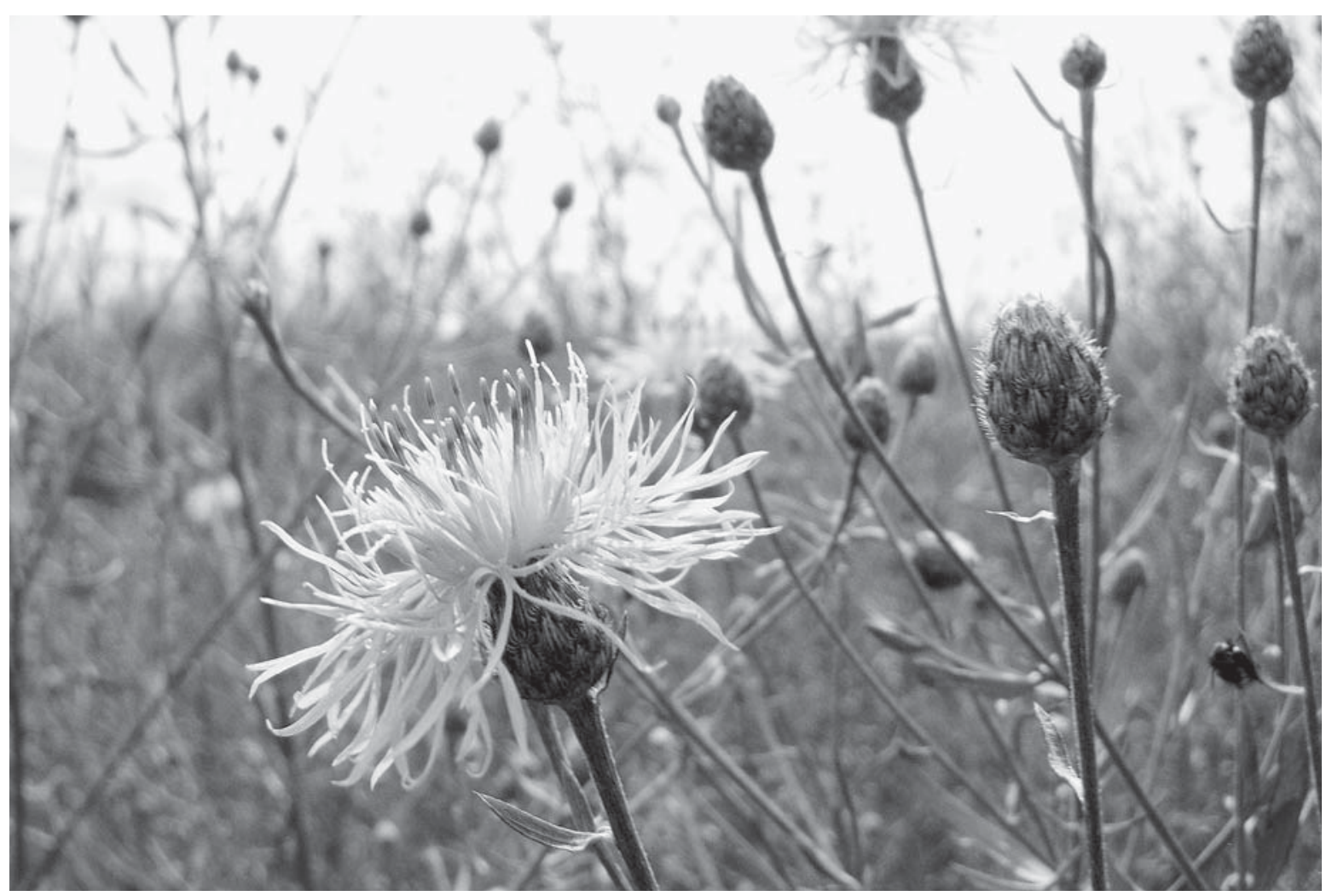

Plate 1. Flowering tetraploid plant of spotted knapweed (Centaurea stoebe; Asteraceae) in the experimental plots in 2008. Photo credit: M. A. Hahn.

found in particular in Eastern Europe (Müller 1989b), which is represented by EU-3 and also EU-1. The observed accelerated phenology in exposure to herbivores might be adaptive, as it may allow the plants to finish their life cycle and set seed earlier and thus, to escape from negative effects of herbivores as shown, e.g., for floral herbivory in Arabidopsis halleri (Kawagoe and Kudoh 2010).

Surprisingly, flowering phenology was differentially affected by herbivory also among the different regions in the introduced range. Plants from NA-1 exhibited a delay due to herbivory, while the opposite was found for plants from NA-3. As, until recently, specialist root herbivores were absent in the introduced range, these regional differences might be caused by different abiotic conditions altering the ability to respond to herbivory, rather than by different evolutionary histories with herbivores.

Interestingly, also European diploids and tetraploids showed different responses to the herbivores. Survival of tetraploids after flowering was increased and they produced accessory rosettes more often, while diploids produced less accessory rosettes in the presence of herbivores. Native tetraploids were in general also more negatively affected as compared to invasive tetraploids, which may indicate differences in tolerance and/or resistance against herbivores among the geo-cytotypes.
Contrary to our expectations, the herbivore treatment did generally not negatively affect plant performance in our experiment, which may most probably be due to the rather low infestation levels. Likewise, previous studies with similar infestation levels reported increased root growth in tetraploids infested with larvae of A. zoegana (Müller 1989a, Müller-Schärer 1991, Callaway et al. 1999), but not in diploids (Steinger and Müller-Schärer 1992). The increased performance of tetraploids, in particular North American tetraploids, as compared to diploids may thus also reflect increased overcompensatory growth capacity resulting from the polycarpic life cycle and the nutrient rich soil conditions (Steinger and Müller-Schärer 1992).

\section{Conclusion}

Our results show contrasting patterns of regional differentiation in life history traits in the three geocytotypes of $C$. stoebe. Besides divergent selection imposed by the abiotic and biotic environment (ecogeographical regions and herbivores) and differences in genetic variation and gene flow (more recent origin and spread of tetraploids in Europe and in particular of the invasive tetraploids as compared to diploids), differences among geo-cytotypes, such as different life cycles (monocarpy vs. polycarpy), appear to modulate patterns of eco-geographical differentiation in C. stoebe. The 
study further revealed the potential of the studied rootmining insect herbivores to increase plant performance, especially in the polycarpic tetraploids, and more so in the introduced populations. Knowledge of these patterns and their potential underlying processes will improve our understanding of the causes of ecogeographical differentiation, its contribution to local adaptation, and of processes underlying invasion success and subsequent biological control interventions. To prevent spurious conclusions in comparative studies, such as in the framework of invasion ecology or conservation biology, we advocate following a comprehensive approach considering all these factors.

\section{ACKNOWLEDGMENTS}

We thank P. Mráz, R. Zindel, W. Hahn, L. Buholzer, D Crottet, J.-B. Haas, M. Stokvis, M. Henery, B. Hall, H. Benson, J. Bielanska, S. Rossinelli, A. R. Collins, A.-K. Schönenberger, and F. Krattinger for assistance in conducting the field experiment; L. Waller for insect collections in North America; the School of Agriculture Grangeneuve, Switzerland, for providing and maintaining the experimental site; Y. Buckley and R. Rohr for statistical advice; and U. Schaffner for helpful comments on earlier versions of the manuscript. H. MüllerSchärer acknowledges funding by the Swiss National Science Foundation (SNSF grant number 31003A_125314, and through the National Centre of Competence in Research "Plant Survival").

\section{Literature Cited}

Bates, D., and M. Maechler. 2009. lme4: linear mixed-effects models using S4 classes. R package version 0.999375-32. http://lme4.r-forge.r-project.org

Bischoff, A., et al. 2006. Detecting local adaptation in widespread grassland species - the importance of scale and local plant community. Journal of Ecology 94:1130-1142.

Bolker, B. M., M. E. Brooks, C. J. Clark, S. W. Geange, J. R. Poulsen, M. H. H. Stevens, and J. S. S. White. 2009. Generalized linear mixed models: a practical guide for ecology and evolution. Trends in Ecology and Evolution 24:127-135.

Bossdorf, O., H. Auge, L. Lafuma, W. E. Rogers, E. Siemann, and D. Prati. 2005. Phenotypic and genetic differentiation between native and introduced plant populations. Oecologia 144:1-11.

Broz, A. K., D. K. Manter, G. Bowman, H. Müller-Schärer, and J. M. Vivanco. 2009. Plant origin and ploidy influence gene expression and life cycle characteristics in an invasive weed. BMC Plant Biology 9:33.

Callaway, R. M., T. H. DeLuca, and W. M. Belliveau. 1999. Biological-control herbivores may increase competitive ability of the noxious weed Centaurea maculosa. Ecology 80: $1196-1201$.

Charnov, E. L., and W. M. Schaffer. 1973. Life-history consequences of natural selection: Cole's result revisited. American Naturalist 107:791-793.

Cole, L. C. 1954. The population consequences of life history phenomena. Quarterly Review of Biology 29:103-137.

Cook, R. E. 1980. Germination and size-dependent mortality in Viola blanda. Oecologia 47:115-117.

Donohue, K. 2002. Germination timing influences natural selection on life-history characters in Arabidopsis thaliana. Ecology 83:1006-1016.

Franks, S. J., S. Sim, and A. E. Weis. 2007. Rapid evolution of flowering time by an annual plant in response to a climate fluctuation. Proceedings of the National Academy of Sciences USA 104:1278-1282.
Galloway, L. F., and C. B. Fenster. 2000. Population differentiation in an annual legume: local adaptation. Evolution 54:1173-1181.

Haggerty, B. P., and L. F. Galloway. 2011. Response of individual components of reproductive phenology to growing season length in a monocarpic herb. Journal of Ecology 99: 242-253.

Hahn, M. A., Y. M. Buckley, and H. Müller-Schärer. $2012 a$. Increased population growth rate in invasive polyploid Centaurea stoebe in a common garden. Ecology Letters 15: 947-954.

Hahn, M. A., M. van Kleunen, and H. Müller-Schärer. $2012 b$. Increased phenotypic plasticity to climate may have boosted the invasion success of polyploid Centaurea stoebe. PLoS ONE 7(11):e50284

Hart, R. 1977. Why are biennials so few. American Naturalist 111:792-799.

Henery, M. L., G. Bowman, P. Mráz, U. A. Treier, E. GexFabry, U. Schaffner, and H. Müller-Schärer. 2010. Evidence for a combination of pre-adapted traits and rapid adaptive change in the invasive plant Centaurea stoebe. Journal of Ecology 98:800-813.

Johnson, M. T. J. 2007. Genotype-by-environment interactions leads to variable selection on life-history strategy in common evening primrose (Oenothera biennis). Journal of Evolutionary Biology 20:190-200.

Joshi, J., et al. 2001. Local adaptation enhances performance of common plant species. Ecology Letters 4:536-544.

Kalisz, S., and G. M. Wardle. 1994. Life history variation in Campanula americana (Campanulaceae): population differentiation. American Journal of Botany 81:521-527.

Kawagoe, T., and H. Kudoh. 2010. Escape from floral herbivory by early flowering in Arabidopsis halleri subsp. gemmifera. Oecologia 164:713-720.

Kawecki, T. J., and D. Ebert. 2004. Conceptual issues in local adaptation. Ecology Letters 7:1225-1241.

Klinkhamer, P. G. L., T. Kubo, and Y. Iwasa. 1997. Herbivores and the evolution of the semelparous perennial life-history of plants. Journal of Evolutionary Biology 10:529-550.

Korneck, D. 2004. Centaurea stoebe subsp. micranthos, Kleinköpfige Flockenblume, eine verkannte Sippe unserer Flora (vorläufige Mitteilung). Hessische Florist Briefe 51:5155.

Leimu, R., and M. Fischer. 2008. A meta-analysis of local adaptation in plants. PLoS ONE 3:8.

Linhart, Y. B., and M. C. Grant. 1996. Evolutionary significance of local genetic differentiation in plants. Annual Review of Ecology and Systematics 27:237-277.

Maron, J. L., M. Vila, R. Bommarco, S. Elmendorf, and P. Beardsley. 2004. Rapid evolution of an invasive plant. Ecological Monographs 74:261-280.

Marrs, R. A., R. Sforza, and R. A. Hufbauer. 2008. Evidence for multiple introductions of Centaurea stoebe micranthos (spotted knapweed, Asteraceae) to North America. Molecular Ecology 17:4197-4208.

Masuda, M., and I. Washitani. 1992. Differentiation of spring emerging and autumn emerging ecotypes in Galium spurium L. var. echinospermon. Oecologia 89:42-46.

Metcalf, J. C., K. E. Rose, and M. Rees. 2003. Evolutionary demography of monocarpic perennials. Trends in Ecology and Evolution 18:471-480.

Mráz, P., R. Bourchier, U. A. Treier, U. Schaffner, and H. Müller-Schärer. 2011. Polyploidy in phenotypic space and invasion context: a morphometric study of Centaurea stoebe s.l. International Journal of Plant Sciences 172:386-402.

Mráz, P., N. Garcia-Jacas, E. Gex-Fabry, A. Susanna, L. Barres, and H. Müller-Schärer. 2012. Allopolyploid origin of highly invasive Centaurea stoebe s.l. (Asteraceae). Molecular Phylogenetics and Evolution 62:612-623.

Müller, H. 1989a. Growth pattern of diploid and tetraploid spotted knapweed, Centaurea maculosa Lam. (Compositae), 
and effects of the root-mining moth Agapeta zoegana (L.) (Lep.: Cochylidae). Weed Research 29:103-111.

Müller, H. 1989b. Structural analysis of the phytophagous insect guilds associated with the roots of Centaurea maculosa Lam., Centaurea diffusa Lam. and Centaurea vallesiaca Jordan in Europe. 1. Field observations. Oecologia 78:41-52.

Müller, H., D. Schroeder, and A. Gassmann. 1988. Agapeta zoegana (L.) (Lepidoptera, Cochylidae), a suitable prospect for biological control of spotted and diffuse knapweed, Centaurea maculosa, Monnet De Lamarck and Centaurea diffusa, Monnet De Lamarck (Compositae) in North America. Canadian Entomologist 120:109-124.

Müller-Schärer, H. 1991. The impact of root herbivory as a function of plant density and competition: survival, growth and fecundity of Centaurea maculosa in field plots. Journal of Applied Ecology 28:759-776.

Müller-Schärer, H., U. Schaffner, and T. Steinger. 2004 Evolution in invasive plants: implications for biological control. Trends in Ecology and Evolution 19:417-422.

Ochsmann, J. 2000. Morphologische und molekularsystematische Untersuchungen an der Centaurea stoebe L.-Gruppe (Asteraceae-Cardueae) in Europe. Dissertationes Botanicae 324.

Pinheiro, J., D. Bates, S. DebRoy, and D. Sarkar. 2009. nlme: linear and nonlinear mixed effects models. R package version 3.1-96. http://cran.r-project.org

R Development Core Team. 2009. R: a language and environment for statistical computing. R Foundation for Statistical Computing, Vienna, Austria.

Reinartz, J. A. 1984. Life history variation of common mullein (Verbascum thapsus). 1. Latitudinal differences in population dynamics and timing of reproduction. Journal of Ecology 72: 897-912.

Richards, C. L., O. Bossdorf, N. Z. Muth, J. Gurevitch, and M. Pigliucci. 2006. Jack of all trades, master of some? On the role of phenotypic plasticity in plant invasions. Ecology Letters 9: 981-993.

Ridenour, W. M., J. M. Vivanco, Y. L. Feng, J. Horiuchi, and R. M. Callaway. 2008. No evidence for trade-offs: Centaurea plants from America are better competitors and defenders. Ecological Monographs 78:369-386.

Roche, C. T., and B. F. Roche. 1991. Meadow knapweed invasion in the Pacific Northwest, U.S.A., and British Columbia, Canada. Northwest Science 65:53-61.

Roff, D. A. 1992. The evolution of life histories: theory and analysis. Chapman and Hall, New York, New York, USA.

Sheley, R. L., J. S. Jacobs, and M. F. Carpinelli. 1998. Distribution, biology, and management of diffuse knapweed (Centaurea diffusa) and spotted knapweed (Centaurea maculosa). Weed Technology 12:353-362.

Silvertown, J., and D. Charlesworth. 2001. Introduction to plant population biology (fourth edition). Blackwell Science, Oxford, UK.

Slatkin, M. 1987. Gene flow and the geographic structure of natural populations. Science 236:787-792.

Stearns, S. C. 1992. The evolution of life histories. Oxford University Press, New York, New York, USA.

Steinger, T., and H. Müller-Schärer. 1992. Physiological and growth responses of Centaurea maculosa (Asteraceae) to root herbivory under varying levels of interspecific plant competition and soil nitrogen availability. Oecologia 91:141-149.

Story, J. M., W. R. Good, L. J. White, and L. Smith. 2000. Effects of the interaction of the biocontrol agent Agapeta zoegana L. (Lepidoptera: Cochylidae) and grass competition on spotted knapweed. Biological Control 17:182-190.

Treier, U. A., O. Broennimann, S. Normand, A. Guisan, U. Schaffner, T. Steinger, and H. Müller-Schärer. 2009. Shift in cytotype frequency and niche space in the invasive plant Centaurea maculosa. Ecology 90:1366-1377.

van Kleunen, M. 2007. Adaptive genetic differentiation in lifehistory traits between populations of Mimulus guttatus with annual and perennial life-cycles. Evolutionary Ecology 21: 185-199.

Welss, W., P. Reger, and W. Nezadal. 2008. Zur Verbreitung von Centaurea stoebe L. subsp. stoebe und Centaurea stoebe subsp. australis (A. Kern) Greuter (Asteraceae) im Nürnberger Becken. Regnitz Flora 2:44-53.

\section{Supplemental Material}

Appendix A

Origins of populations of $C$. stoebe used in the experiment

\section{Appendix B}

Eco-climatic niche space of populations of the three geo-cytotypes of $C$. stoebe

\section{Appendix C}

Comparisons of life history traits of the three geo-cytotypes of C. stoebe from different eco-geographical regions 